\title{
Modern Arts of Governing the Use of Pesticides in Malaysia
}

\author{
PETER TRIANTAFILLOU
}

\section{Abstract}

This article presents an analysis of contemporary struggles over the use of pesticides in Malaysian agriculture. Drawing on Michel Foucault's genealogical analyses of power/knowledge relations in modern societies in general, and governmental rationalities evolving around the management of populations (bio-power) in particular, the article presents three main arguments. First, in order to tell the truth about pesticide poisoning one had to resort to medical and toxicological discourses which proved to be important for validating and invalidating claims made on the poisonous effects of pesticides. The possible modalities by which the use of pesticides could be contested were, in effect, technicalized and importantly restricted. Second, the attempts to govern and contest the use of pesticides on the grounds that it presented a threat to public health had as an important precondition the recasting of development discourse in Malaya between 1945 and 1955. The associated transformation of public health policies, which implied that the promotion of the population's health standard became a domain for regulatory intervention, at one and the same time created a possibility to regulate and protest over the use of pesticides. Third and finally, contestation over the use of pesticides, on the basis that it presented a threat to public health, tended to be reduced to a conflict over the effectiveness and implementation of regulatory techniques.

\section{Introduction}

Contemporary Malaysia is witnessing a clash of conflicting rationalities related to modern forms of pest control. The undesirable side-effects of chemical pesticides, the use of which proliferated in Malaysian agriculture after World War II, on human health and the environment were pointed out by crop protection scientists in the 1960s. Although a legal framework was established in the early 1970 s to control the side-effects of pesticides by mandatory 
registration and quality control, the public opposition to the use of pesticides continued and from around 1980 the 'pesticide problem' was a matter of intense debate in the Malaysian public sphere.

One approach to the contestation and regulation of pesticide use in Malaysia could be to see the rise of new values and norms, including an increasing awareness of health and environmental problems, as a result of the increasing modernization and development of Malaysian society. Measures to control the problems caused by pesticides and promote alternative forms of pest control as propagated by the NGOs and certain agricultural scientists, the story would go, have been stalled by vested economic interests of the pesticide industry and estate owners. In the semi-democratic polity of Malaysia, the government, preoccupied with economic growth and development, has responded only slowly by formulating and implementing various more or less effective policies to control health and environmental problems caused by pesticides.

It is not that this approach is incorrect or an unfruitful mode of analysis. For instance, the approach could probably serve as an excellent entry to a policy process analysis which could establish the differentiation of interests and strategies found within and between economic interest groups, NGOs and policy-makers in the state apparatus. Yet, it leaves little space, I think, for illuminating the construction of categories, assumptions, truths and knowledges which today are taken for granted; constructions which have crucial implications for the way that the use of pesticides in Malaysia was problematized and governmentalized. More precisely, this approach renders it absolutely impossible to analyse how the making of public health as a domain of interventions through scientific discourses came to have crucial implications for the way that one could possibly govern and contest the use of pesticides. More importantly, it does not provide a means of analysis for the way that

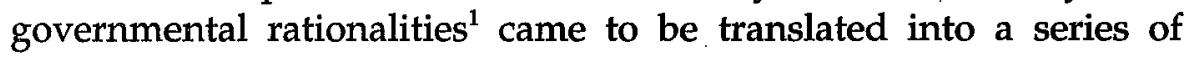
disciplinary techniques aiming to influence the behaviour of farmers and plantation workers in relation to their application of pesticides.

\section{Analytical Perspective and Arguments}

This article tries to analyse the importance of scientific discourses and governmental rationalities in the struggle over the pesticide use in Malaysia by drawing on Michel Foucault's genealogical approach in the study of historical formations and transformations of 
power/knowledge relations (Foucault 1979; 1980; 1990; 1991b). It is, of course, impossible to produce any account of Foucault's genealogical approach in this article. Hence, the following only outlines, in the briefest fashion, some key notions giving rise to three main arguments presented in the article.

The first argument revolves around the importance of scientific discourses in regulating and restricting the struggle over pesticides, and takes as its point of departure Foucault's notion of a 'regime of truth'. Foucault introduced the notion of 'regime of truth' to point to the interrelatedness between power and truth: that they directly imply one another, and that their very existence is preconditioned by each other. Thus, the important thing to note, argues Foucault, is that:

Each society has its regime of truth, its 'general politics' of truth: that is, the types of discourse which it accepts and makes function as true; the mechanisms and instances which enable one to distinguish true and false statements, the means by which each is sanctioned; the techniques and procedures accorded value in the acquisition of truth; the status of those who are charged with saying what counts as true (Foucault 1980: 131).

One of the main characteristics of the regime of truth found in modern societies, argued Foucault, is that it is 'centred on the form of scientific discourse and the institutions that produce it' (Foucault 1980: 131). In other words, scientific discourses, the people who articulate them, and the institutions reproducing them, are granted a unique authority in modern societies.

In contesting the use of pesticides in Malaysia on the basis of the poisonous effects this had on human beings - and this is the first argument of this article - one resorted to scientific discourses to be taken seriously. More precisely, only by resorting to medical and toxicological discourses was it possible to tell the truth about pesticide poisoning, and more importantly to speak with authority. The effect of this politics of expert knowledge, that is, the attempts to validate and invalidate claims of the effects of pesticides by resorting to scientific discourses, was to technicalize and restrict the possible modalities by which the use of pesticides could be contested.

The second and third arguments revolve around Foucault's notion of 'governmentality' and 'bio-power'. Governmental rationalities, that is, the questions of 'How to govern oneself, how to be governed, how to govern others, by whom the people will accept being 
governed, how to become the best possible governor' became crucial issues in Western societies from the 16th and 17th centuries. As pointed out by Foucault these problems marked a radical rupture from the line of advice found in Machiavelli's The Prince. What is at stake is less how to reinforce, strengthen and protect the prince's relation to his territory than how to govern most effectively the men and things in their relations with one another within a territory (Foucault 1991b: 87). Government came to designate a relation internal to the state, namely the art of conducting the conduct of men. Governmental rationalities, or just governmentalities, as they have emerged in Western societies for the last four centuries, then, could be conceived as the relatively systematic, explicit, discursive problematization and codification of the art or practice of government, as a way of rendering objects in a language that makes them governable (Dean 1994: 187).

Bio-power is a key aspect of modern governmentalities. In The Order of Things, Foucault (1970) demonstrated that life, conceived as an organic functional being, is not an eternal object but only entered Western European thought at the end of the 18th century. In The History of Sexuality, Foucault would subsequently argue that life at this time became not only an object of knowledge, but also of power and administration. Bio-power emerged as an ensemble of new forms of knowledge and techniques of government, the aim of which was to administrate life at the level of the human species, the race, and the phenomena of population (Foucault 1990: 137).

Bio-power designates the techniques through which life and its mechanisms are brought into the realm of explicit calculations, and relations of power/knowledge are made an agent of transformation of human life (Foucault 1990: 143). The power over life, according to Foucault, evolved around two basic forms of techniques linked together by a complex set of relations: the disciplines of the body and the regulations of the population. The first set of techniques, the 'anatomo-politics' of the human body, aimed to discipline the individual human body. Procedures were established which centred 'on the body as a machine: its disciplining, the optimization of its capabilities, the extortion of its forces, the parallel increase of its usefulness and its docility, its integration into systems of efficient and economic controls' (Foucault 1990: 139). 
The second set of techniques, the bio-politics of the population, focused on the species body, and dealt with the mechanisms of life and biological processes: 'propagation, births and mortality, the level of health, life expectancy and longevity, with all the conditions that can cause these to vary' (Foucault 1990: 139). These regulatory controls were associated with new types of knowledge, such as demography and statistics, through which it is gradually 'discovered': first, that population has it own regularities, its own rate of mortality and diseases, its cycles of scarcity, etc.; second, that population involves a range of intrinsic, aggregate effects, phenomena that are irreducible to those of the family, such as epidemics, endemic levels of mortality, ascending spirals of labour and wealth; and lastly, that population has specific economic effects (Foucault 1991b: 99; see also Hacking 1982).

The second argument, then, is that the promotion of the safe use of pesticides in Malaysia on the grounds that it presents a threat to the health of the population only became possible once the standard of the health of the population, or segments thereof, was taken up by biopower as a domain for the deployment of regulatory interventions. It is illustrated that although a comprehensive medical apparatus had been elaborated by the British colonial administration from the end of the 19th century, it was only after the recasting of development discourse between 1945-55 that the population's standard of health became an object for public policies. This transformation of public health policies was a precondition for the subsequent call for the regulation of the use of pesticides on the ground that it presented a threat to the population's standard of health.

Third and finally, contestation over the use of pesticides, on the grounds that it presented a threat to public health, tended to be reduced to a conflict over the effectiveness and implementation of regulatory techniques. That is, what has been questioned is not the need for government policies to promote the safe use of pesticides, but the effectiveness, adequacy and the level of implementation of these initiatives. This is not to say that alternatives to techniques of government aiming to promote the safe use of pesticides have not been sought. For instance, the NGOs have during the early 1990s engaged themselves in what is still limited, but none the less important alternative forms of agricultural production without using chemical pesticides. Rather the point is that governmental rationalities have served constantly to update the techniques aiming to promote public 
health: every time government intervention is seen to fail, governmentalities hold the promise to monitor, control and regulate the use of pesticides through either more strict enforcement of existing techniques, or the introduction of new and allegedly more effective ones.

\section{The Transformation of Public Health Policies through Development Discourse}

Public health policies underwent an important transformation in relation to the recasting of development discourse between 1945-55 in that the promotion of the population's standard of health was taken up as an issue for government. This was absolutely crucial for the way that the use of pesticides was subsequently to be problematized.

The promotion of the economic progress of the Malay states was a crucial rationale for the efforts invested to prevent and cure diseases among the 'natives' from around 1870s, when, in relation to the efforts of the British colonial administration to promote order and progress, the question of government became an issue of unprecedented importance in the Malay states (cf. Annual Report of the Federated Malay States, 1895-1935). The 'opening-up' of the Federated Malay States from the 1870s, with new mining and planting areas, new roads and railways, and new townships, was accompanied by a dramatic rise in diseases such as malaria, beriberi, dysentery, smallpox and cholera (Kennedy 1962; Gullick 1969). The horrendous extent of disease was seen to present a real threat to the task of developing the Malay states, and a number of important measures were taken from the 1880s to the 1940s, to prevent and cure diseases both among Europeans and non-Europeans. The effects of these measures were quite impressive. The incidence of smallpox, beriberi and malaria was significantly reduced in the first quarter of this century by introducing preventive vaccinations, complementary diets, and drainage respectively. For instance, between 1910 and 1920 the death rate among estate labourers due to malaria was reduced by two-thirds, and between 1910 and 1925 the overall death rate in Peninsular Malaya dropped from 32.2 to 23.6 per 1,000 (Report on the Federated Malay States, 1910-25). By the second quarter of this century Malaya was seen as having the best medical and health services in Asia (Balfour and Scott 1924: 150-55). 
Notwithstanding the effectiveness of the measures deployed to cure and prevent diseases, they were not intended to improve the general welfare of the people of the Malay states, but rather to ensure that diseases did not hinder economic progress. The rationale for the health policies conducted in the Malay states fitted into the general British health policy for its colonies. Thus, in the British Colonial Development Act 1929 the 'promotion of public health', though an important part of colonial policy, was seen as only one among many other means to contribute to the 'advances for aiding and developing agriculture and industry in certain colonies and territories' (Colonial Development Act 1929). The British policy on the health of its colonial subjects significantly changed in the 1940s, with crucial ramifications in Malaya. The British Development and Welfare Act 1940 set forth for the first time at the level of colonial public policies, the promotion of the welfare and development of the colonial populations. Public health was to be an important element in the attempts to promote the welfare of the native populations. Thus, the connection between development of productive resources on the one hand, and the progress of the living standards of the colonial subjects on the other, was spelled out in the Colonial Office's The Planning of Social and Economic Development in the Colonial Empire like this: 'Health, wealth and wisdom each help in the attainment of the others; and forward steps in the spheres of production, public health and education are not merely mutually compatible, they are mutually essential' (Colonial Office 1944: 3). This shift in the strategic objectives of British colonial policy was to be crucial for Malaya.

Public health policies in Malaya underwent a radical transformation in the period 1945-55 when, through the recasting of development discourse, the promotion of the welfare standard of the population became a task for government. It is beyond the scope of this article to document how this transformation took place, only brief indications can be given by pointing to two important documents. In 1949, the year after the British colonial power had committed itself to prepare for the independence of Malaya, the British High Commissioner initiated the work on the first comprehensive plan of the economic and social development of Malaya. With the Draft Development Plan of the Federation of Malaya issued in 1950, Malaya became, for the first time, equipped with a plan that attempted to 'define the objectives of social and economic 
policy for the period 1950-55: to balance them in relation to each other, and to plan them within range of the resources available to finance them' (Draft Development Plan of the Federation of Malaya 1950: i). In meeting 'the demands of the people for social services and social justice' and improving 'the conditions under which people live', which was seen as the central task for government, public health programmes were to play an important role (ibid.: i). Thus the Draft Development Plan of the Federation of Malaya allocated substantial resources to the establishment of a training school for local medical personnel, rural health services, treatment of tuberculosis, improvement of general hospitals, and medical research (ibid.:10-11).

The report The Economic Development of Malaya, produced by a Mission from the International Bank for Reconstruction and Development in 1955, was the hitherto most comprehensive analysis made on the 'need' for social and economic development, and the potentials and obstacles to accomplish this. It served effectively to carve out the developmental imagery that persists largely unmodified in contemporary Malaysia, namely that of a 'society' in need of 'development'. On public health and medical care, the report found that the colonial administration had made 'outstanding achievements' in improving public health and medicine but much remained to be done. There were several reasons for the need for further improvement. One reason was that 'environmental controls' were no longer seen as sufficient to improve public health; it would increasingly be necessary to apply 'personal services' which were much more expensive. Another reason was that as the population kept growing, an increasing number of people were to be served. Finally, the fact that 'all racial groups in the population now increasingly accept and expect "western medicine", and have begun to demand clinic and hospital services' was taken as a further proof of the need for expansion of public health programmes and expenditures (The Economic Development of Malaya 1955: 547).

What was new about the Draft Development Plan of the Federation of Malaya and The Economic Development of Malaya was not the deployment of government programmes aiming to prevent and cure illnesses in the Malayan population. As illustrated, comprehensive measures had taken place on this issue from the late 19th century. The new thing was that these measures intended no longer primarily to enable and sustain the development of economic resources, but to improve the general welfare standard of the body species. 
The transformation of bio-power meant that the population's standard of health became a target of knowledge and regulatory intervention. Population statistics had been introduced as early as the 1880 s, when the population's size, movement, racial and spatial distribution came to be known. From the 1940s there suddenly emerged a need for more systematic and comprehensive knowledge of the population's standard of health. Thus, it becomes urgent to produce comprehensive and reliable statistical data on the causes of sickness and death, infant mortality, and average life expectancy (The Economic Development of Malaya 1955: 548-50). The population's health standard, measured by the new statistical knowledge, was now to be promoted through expansion and improvement of government services: training and expansion of staff; modernization and extension of the hospital system; expansion of ambulatory care facilities; the development of a network of rural health centres; initiation of research and educational campaigns on nutrition, etc. (The Economic Development of Malaya 1955: 148-53). These and other public health programmes were further expanded in the decade following Independence in 1957, and substantial parts of government expenditure were invested to bring about their implementation (cf. First Malaysia Plan 1966-1970).

\section{The Governmentalization of the Use of Pesticides}

The problematization of the use of pesticides from the perspective of public health has largely taken two lines: concern over 'occupational' health problems, that is, poisoning of farmers and plantation workers during application of pesticides; and concern over 'consumer health', that is, poisoning of consumers caused by pesticide residue in food items.

The threat to the health of farmers and plantation workers posed by poisoning with pesticides was first politicized in the late 1970s in various newspaper articles, NGO journals and at conferences held by the NGOs and the agricultural scientific community (Gill 1978; Ong et al. 1978). The first comprehensive critique of the use of pesticides was launched by Sahabat Alam Malaysia, SAM (Friends of the Earth Malaysia) in 1981. In the booklet Pesticide Problems in a Developing Country - A Case Study of Malaysia, SAM pointed out the negative effects caused by pesticides on human health and the environment, and claimed that Malaysia had become a 'dumping 
ground' for pesticides banned in industrialized countries. More importantly, the Pesticides Act adopted in 1974 was criticized for being inadequate and not fully enforced, and the Pesticides Board was urged together with the Health Ministry to 'play their roles in educating the farmers as well as the general public on the safe and proper use of pesticides' (Sahabat Alam Malaysia 1981).

The struggle over pesticide poisoning of farmers and plantation labour in the 1980s focused on the incapability of the government to monitor and control the use of pesticides. For instance, SAM, in an infamous article pointing to the numerous incidents of pesticide poisoning among plantation workers, argued that the government's Pesticides Board had not lived up to what could be expected, hence, it 'should be scrapped and replaced with a fully-fledged department with effective powers to regulate and control the pesticide industry in Malaysia' (Sunday Star, 19.2.1984; Malay Mail (MM) 21.3.1984). ${ }^{2}$

Attention to pesticide residues in food was first raised in the late 1970s by various natural scientists (e.g. Gill 1978: 179; MM 20.2.1978), but concern only gathered momentum in 1987 when the Singapore Ministry of Environment found fungicide residues (ethylene bisdithiocarbamate, EBDC) in spring onions imported from the Malaysian Cameron Highlands to be between 20 and 50 times above the level permitted in Singapore (New Straits Times (NST) 2.3.1987). Singapore authorities subsequently decided to deploy a provisional ban on the import of spring onions and certain other vegetables from Malaysia (Star, 4.4.1987). When subsequent testings conducted by the Malaysian authorities showed that many leafy vegetables from the Cameron Highlands (which is the main centre for commercial vegetable production in Malaysia) also contained pesticide residues in concentrations exceeding WHO standards, the Malaysian government made a public announcement in which it advised consumers to avoid eating seven types of vegetables from the Cameron Highlands (NST 4 and 5.3.1987).

In the quite strident public debate that followed in the weeks after Singapore's import ban and the revelation of 'excessive' levels of pesticide residues in vegetables from the Cameron Highlands, the demand for government action was raised from several locations. State Assemblyman for the city of Tanah Rata (in the Cameron Highlands) said that it was 'unfair' to blame the farmers for the excessive use of fungicides. Rather 'The Agriculture Ministry should 
have played a more active role in monitoring and supervising the application of fungicides'. He added that 'Most of these farmers are uneducated and need more expert advice and supervision' (Star, 6.3.1987). Many NGOs called for governmental intervention along similar lines by urging the government to take responsibility for poisoning incidents and to carry out regular tests of pesticide residues in fruit and vegetables both in the fields and at the markets. There can be no doubt that the protest over the use of pesticides from the early 1980s was influential in the implementation of measures to counteract these problems. Yet it should be noted that the issue had been taken up as a task for government a decade before, when a quite comprehensive legislation and a government body were established to control the hazards to human health and the environment caused by pesticides.

The document The Need for Pesticide Legislation in Malaysia, issued in 1974 by the Plant Protection Services of the Division of Agriculture, explains why it was 'necessary' to take up the use of pesticides in relation to public health as a matter of public policy:

During the past quarter of a century nations in all parts of the world had benefited from increasing use of synthetic organic chemicals for the control of pests, diseases, weeds, etc. These chemicals are biological poisons and therefore, recognized precautionary measures must be taken to protect human health and prevent serious ill effects in the various stages of manufacture, storage, transportation and use (Balasubramaniam 1974: 1).

The objective of the Pesticides Act adopted in 1974 was briefly stated to be: 'An Act to control pesticides'. A more expanded formulation given later stated that the Act's objective is five-fold:

(1) to control manufacture, sale and storage of pesticides in the country;

(2) to ensure that pesticides are effective as claimed on the label;

(3) to control adulteration with respect to its contents, concentration of active ingredients, efficacy and other characteristic of the pesticides;

(4) to control pesticide residues in food for local use and also for export; and

(5) to control pesticide hazards to users, operators, the public, domestic animals, water sources and the environment (Department of Agriculture 1989).

The Pesticides Act 1974 came to be based partly on elements contained in the Voluntary Registration Scheme initiated in 1971, and partly on 
an unpublished FAO report produced in 1972 by the Government of Malaysia which outlined detailed suggestions on technical and organizational measures for a licensing scheme (cf. Boardman 1986: 160). The Pesticides Act required a number of technical data for registration of the individual pesticide product including:

- composition of the product;

- chemical designation of active ingredients;

- efficacy on pest/diseases of crops;

- dosage and number of applications recommended;

- directions for use;

- amount and nature of residue left on crops at various intervals after application;

- analytical procedure; and

- toxicity of the product

(Pesticides Act 1974; Pesticides (Registration) Rules 1976).

A new government agency, the Pesticides Board, was set up in 1974 within the Plant Protection Unit in the Ministry of Agriculture to implement the Act. In practice the Pesticides Board serves to ensure that all relevant technical government bodies participate in decisionmaking of principal importance, such as the making of new regulations. If the Pesticides Board primarily has a representational function, the Pesticides Section (likewise placed in the Plant Protection Unit) is in charge of conducting the everyday work of pesticide registration, formulation control, bioefficacy, toxicological testing and licensing control (Malaysian-German Pesticide Project 1993: 26-32).

In summary, considering that the use of pesticides was not an issue of intense dispute before 1980, it may seem rather curious that the Malaysian government by the early 1970s had invested substantial efforts in putting together a comprehensive legislation and establishing a technical body to control pesticides. That is, apart from a few agricultural scientists who had raised the issue of the build-up of resistance to certain insecticides (Conway and Wood 1964; Wood 1968; 1971), public attention to the problems that pesticides might cause to public health and the environment was at a very low level. One should not, of course, ignore the fact that the dangers of pesticides had been increasingly politicized in the industrialized countries during the 1960s. Nor should it be ignored that the issue had been taken up by the Food and Agricultural Organization (FAO) and the World Health Organization (WHO) in 
the late 1960s and that they in collaboration produced a set of guidelines for the regulation of pesticides in developing countries (cf. Boardman 1986). While there can be no doubt that these events influenced the timing of the Malaysian government's decision to create legislation and an institution to control pesticides, it should be stressed that these measures aiming to protect standards of public health only made sense due to the way development discourse had been recast between 1945-55. i.e. when the protection and improvement of public health standards became a key objective for regulating the population.

The making of a pesticide policy in Malaysia in the early 1970s, then, had very little if anything to do with public awareness of, or objections over, the use of pesticides. Rather this should be seen in relation to the conjuncture of, on the one hand, the transformation of bio-politics that made the improvement of the population's health a key objective, and on the other hand, the circulation of medical and toxicological discourses from the 1960s, through for instance FAO and WHO reports, which made visible the toxicological threats to human health posed by pesticides.

\section{Telling the Truth about Pesticide Poisoning}

Toxicological and medical discourses assumed a crucial role in the debates over the use of pesticides. A brief illustration of the categories, truths and assumptions found in the Guidelines on Toxicological Data Requirement for Pesticide Registration issued by the Pesticides Board may be useful. The introduction reads:

Toxicological data are submitted for pesticide registration aimed at defining possible hazards to man, non-target organisms and the environment ... Many practical recommendations can be derived from appropriate and thorough toxicological data such as hazard classification, restrictions on use, appropriate precautionary measures necessary to allow safe use, suggestion of appropriate diagnosis and management of a poisoned person, establishment of Acceptable Daily Intake (ADI) etc. ${ }^{3}$

In these few lines the intersection between toxicological discourse and governmental rationalities is pointed out with remarkable precision: from appropriate and thorough toxicological data can be derived a number of 'appropriate measures' to allow the 'safe use' of 
pesticides. The notion of 'hazard classification' is crucial because it actively displaces the irregularity of individual poisonings, which in some cases lead to slight indispositions and in other cases to death, by an average measure of danger based on clinical experiments in which test animals are exposed to controlled levels of pesticides. As a measure of danger, 'hazard classification' shifts the attention from individual and random poisoning accidents caused by a particular set of agricultural practices, to an expected severity of poisoning caused by exposure to a particular pesticide. In fact, from the perspective of hazard, poisoning is not accidental at all, but the measurable, regular and normal effect of exposure to pesticides.

Whereas the problem of random individual poisoning incidents does not allow prediction of accidents and hence point either to the outright acceptance of the use of pesticides (fait accompli) or its total elimination, the problem of hazard makes possible general measures of restriction and prevention so as to allow the continued but 'safe' use of pesticides. Medical and toxicological knowledge enables the establishment of correct and 'appropriate diagnosis', and the subsequent 'management' of poisoning incidents. Pesticide poisoning is not a random or accidental phenomenon caused by a certain modern modality of pest control, but rather a predictable and normal 'side-effect' of pesticides which can be controlled by the deployment of appropriate techniques of medical diagnosis and management.

Likewise, by establishing a general set of calculated levels of pesticide intake, below which the human body will not display poisoning symptoms, the category of Acceptable Daily Intake makes it possible to continue the use of pesticides in a controlled and 'safe' manner. Thus, for each food item consumed in Malaysia, the Food Regulations 1985 define a Maximum Residue Level, i.e. the upper limit of allowed pesticide residue concentration in each food item. The establishment of the Maximum Residue Levels is by no means arbitrary, but follows WHO standards which, in turn, are based on controlled medical and toxicological studies to determine the level below which the toxic effects of pesticides in specific food items are 'insignificant'

Attention to the harmful effects of pesticides reached hitherto unprecedented heights in 1985, when an international campaign on the harmful effects of twelve of the most abundantly used and hazardous pesticides, 'The Dirty Dozen' campaign, was launched by 
the Pesticides Action Network (PAN). ${ }^{4}$ The Dirty Dozen campaign's dissemination of scientific knowledge on the negative effects of pesticides and its disclosure that several of the Dirty Dozen pesticides used in developing countries were either severely restricted or banned in industrialized countries, drew substantial attention to the negative effects of pesticides in both industrialized and developing countries.

The Dirty Dozen campaign coincided with a number of efforts to document the 'real' extent of human pesticide poisoning in Malaysia. The Pesticides Board in 1985 to be informed of all pesticide poisoning cases reported to the government hospitals and clinics. A computerized database of poisoning cases was established in 1987 by the Toxicology Unit of the Pesticide Section to serve as a basis for decisions on the registration, deregistration or re-registration of pesticides (Malaysian-German Pesticide Project 1993: 90). The Occupational Health Unit of the Division of Health of the Ministry of Health began from 1986 to collect and publish information on incidents of pesticide poisoning and pesticide residues in food (cf. Ministry of Health Annual Report).

The statistics on pesticide residues published by the Ministry of Health produced rather predictable, but none the less interesting differences of opinion. On the one hand, the NGOs in general found the figures worrying. For instance, the President of the Environmental Protection Society Malaysia, Gurmit Singh, found the 1992 survey results disturbing because they showed that $9.2 \%$ of the test samples exceeded the Maximum Residue Levels (NST, 15.3.1994). On the other hand, most officials from the Ministry of Agriculture and the Ministry of Health, and researchers from the Malaysian Agricultural Research and Development Institute and the Agricultural University (Universiti Pertanian Malaysia) all agreed that the incidence of pesticide residues in Malaysian food was not alarming. For instance, when the figures for 1992 were presented, Assistant Director of the Food Quality Control Unit, Ministry of Health, Dr. Anuar Ariffin said: 'consumer perceptions of risk do not usually coincide with the actual hazard involved for many food safety issues as seen from the scientific angle or that envisaged by food control organizations' (NST, 15.3.1994, my emphasis). In a comment on the figures for 1993, Dr. Anuar Ariffin commented: 
Exact permissible levels are set as means of control, but exceeding this by a fraction need not constitute an instant health hazard. The panic begins because consumers reject the safety margin and say they do not want any chemicals used in food production. There is a need to see the risk from a practical perspective and strike a balance in managing it (NST, 2.5.1994).

If worries over the level of pesticide residues in food were to be taken as valid and authoritative, they should not simply refer to the deceiving 'perceptions', but to the 'scientific angle', i.e. toxicological discourses, which allowed you to speak of the 'actual hazard' involved. The occurrence of pesticide residues in food was not to be judged on individual and random perceptions, but according to a calculated level of risk. By rendering possible the establishment of a 'safety margin' (i.e., the level below which exposure to pesticides did not constitute a risk to human health), toxicological discourses simultaneously enabled the continued use of pesticides in a controlled and 'safe' manner.

Three other examples may illustrate how claims uttered on the effects of pesticides tried to validate and authorize themselves by resorting to toxicological and medical discourses, and how this in turn affected the struggle. First, in a newspaper article under the headline 'Truth about Paraquat', the legal advisor of the Consumers' Association of Penang (CAP) responded to an advertisement by ICI Agrochemicals on paraquat with the rather provoking text: 'Paraquat and Nature working in perfect Harmony' (NST, 6.7.1993). CAP's legal advisor argued that 'the claims made in the advertisements [of paraquat not being harmful to aquatic life and wildlife] have not been substantiated by independent research bodies' (ibid.). To counter the unsubstantiated claims made in the advertisement, CAP referred to tests made by foreign scientists, such as the United States Environmental Protection Agency, which had shown that paraquat, though absorbed by clay particles in the soil, could still contaminate groundwater. Raman added that a toxicologist of the US Environmental Defense Fund had found that paraquat could bring 'potential environmental contamination and damage to health' (NST, 6.7.1993). In the same newspaper article, a spokesperson for ICI Agrochemicals, when asked about the purpose of the advertisement, said that it was a campaign to clear the 'myths' about paraquat and defend the product for what it 'really' is: 'Our claims are substantiated 
by research done by ICIA and certain independent research groups' (NST, 6.7.1993). Now, while it is correct that ICI has undertaken and published several studies of paraquat use in Malaysian agriculture which, stated in admittedly very brief terms, show that the occupational health problems are negligible and can be avoided by few and simple measures of precaution (Chester and Woolen 1981; Howard et al. 1981; Whitaker 1989) the bulk of 'independent' research shows that even low-level exposure to paraquat may cause skin rashes, blistering, damage to the nails, and eye irritation $(\mathrm{Ng}$ and Thong 1978; Chan and Cheong 1982), and that the equipment necessary for adequate human protection against poisoning is very difficult to wear and apply in tropical climates (e.g. Conway 1991: 110). The point, however, is not whether it is ICI Agrochemicals or $\mathrm{CAP}$ who has got the 'facts' right, but that it is deemed necessary to resort to scientific discourses to 'substantiate' or validate any argument on the presumed danger of pesticides. In order to speak with authority, propositions could not be based on 'emotional' thought, nor merely on the 'perceived' dangers caused by pesticides. Rather one had to appeal to medical discourses in general and toxicological discourses in particular to tell the 'truth' about pesticide poisoning.

The second example may illustrate how pesticide poisoning was conceived as an object represented by a perceiving subject. To make the true representation of the object, the subject could not rely arbitrarily on his or her perceptions but had to resort to scientific discourses. In an editorial of the pesticide industry's newsletter it was argued that:

The Pesticide Industry in Malaysia (and in the world) is very much misunderstood. The benefits of the (correct) usage of pesticides are often masked by the fears (real or perceived) of the harm pesticides can do to the environment, animals and, most importantly, to humans. Often these fears are unfounded and the subsequent 'panic' a result of emotional rather than logical thought (MACA Newsletter, 1

(1) 1988; cited from reprint in MACA Newsletter, 6 (1) 1994).

The 'real' danger of pesticides was to be located as a property of the pesticide as such, that is, pesticides conceived as an object in itself. In contrast, the 'perceived' danger was seen as the 'distorted' representation produced by the perceiving subject who, when driven by emotions, was no doubt prone to make erroneous observations on the true character of the pesticide-object. Now, it does not take much 
to see that what is at play here is the tension invoked by the modern Western invention of the division between 'the-thing-in-itself' and 'the-thing-for-us'; the tension between the truth of the mute object and the deceiving senses of the truth-searching subject. ${ }^{5}$ While at first this may seem to be of remote interest to the concrete struggle over pesticides in Malaysia, it must be recognized that the authority of any statement made in relation to the use of pesticides came to hinge on the ability to utter the 'true' representation of the thing-initself, that is, pesticide poisoning as an object in itself. And it is exactly at this point that scientific discourses enter into the politics of truth, because the only way one could produce the 'true' representation of the object of pesticide poisoning was by resorting to scientific discourses, notably medical and toxicological discourses.

The third and final example illustrates how the politics of expertise turned out to have unintended consequences for the critics of pesticides. In 1984 SAM had launched a harsh critique of the Pesticides Board which was accused not only of being a 'sleeping watchdog', but also lacking 'expertise' to undertake studies on the effects of the widespread use of pesticides in Malaysian agriculture. As an example of the Board's insufficient expert knowledge and research capacity, SAM pointed to the Board's approval of the use of the pesticide 2,4,5-T despite the fact that research findings of the US Environmental Protection Agency had shown that it contained dioxin which was found to be linked to spontaneous abortions (Star, 19.2.1984). The critique was not without effect. The Chairman of the Pesticides Board (and Deputy Agriculture Minister) Abu Bakar, after insisting on the value of the Board's research and regulatory initiatives, to a certain extent accommodated the critique by stating that: 'They [SAM and CAP] should understand our problems. There are thousands of pesticides on the market and it is difficult to monitor them all' (Star, 26.2.1984).

The engagement in the politics of expertise was however to backfire on SAM only the following year. In a newspaper article SAM. claimed that Monsanto had decided to withdraw the herbicide Scout from the market because it could cause 'parthenocraphy [sic.], a disease affecting the lungs and causing other health problems' (Sunday Star, 26.5.1985). A Monsanto spokesperson immediately rejected SAM's allegations and explained that the term 'parthenocarpic' is a botanical term designating the development of fruits without the 
fertilization of the ovules. The spokesperson added that he 'hoped SAM would get its facts right before making any allegations' (Star, 28.5.1985). Also Pesticides Board Chairman, Abu Bakar, rejected SAM's allegations, and posed an explanation of the term 'parthenocarpy' similar to that given by the Monsanto spokesperson. He concluded: 'the claim that SAM made was not true' (Star, 2.6.1985). SAM, in turn, had to admit that it was 'wrong', and SAM's President added that: 'We are very glad Monsanto has now clarified the issue in the interest of all concerned' (Star, 29.5.1985).

In summary, two rather contradictory effects were produced by the NGOs' resort to scientific discourses to validate their propositions. On the one hand, by basing their criticism of pesticides on 'facts', the government and the industry could no longer disqualify this type of criticism as being only 'emotional'. The criticism had to be taken seriously and, as will be illustrated in the following, both the government and the industry from the mid-1980s expanded the measures aiming to regulate the problem. On the other hand, by resorting to medical and toxicological discourses to utter the truth about pesticides in relation to human health, the NGOs contributed to the reinforcement of these regimes of truth. By entering effectively into the politics of expertise in which one had to adhere to the 'facts' and 'logic' produced through scientific discourses, the possible modes of criticism were at the same time being severely restricted. The politics of pesticide use, in this way, was reinforced as a matter to be dealt with by experts. If the NGOs increasingly resorted to scientific discourses, this was hardly because they were unconscious about the consequences this could entail, but rather because this was the only way to tell the truth about pesticides, and more importantly, because this was the most effective way of validating claims over the poisonous effects of pesticides. Conversely, the resorting to scientific discourses by the Ministry of Agriculture and the pesticide industry should not be seen as an excuse to dismiss criticism. Rather, they were resorting to the modality in which one could speak in the most authoritative manner about the health effects caused by pesticides. 


\section{Disciplining Farmers in Their Use of Pesticides}

'No pesticide is entirely without risk, but there are many ways of using them safely and efficiently.' (Mamat 1989)

The Ministry of Agriculture in 1978 submitted a request for technical assistance to the West German aid organization GTZ in order to implement the Pesticides Act and 'to train local chemists on residue analysis and also to obtain foreign expertise and equipment in the establishment and operation of a new pesticide residue laboratory' (Malaysian-German Pesticide Project 1993: 3). After years of negotiations the Malaysian-German Pesticide Project (MGPP) was initiated in 1984, the overall goal of which was to ensure that 'damage to man and the environment caused by pesticides is minimized' (MalaysianGerman Pesticide Project 1993: 8).

The problem of minimizing the 'damage to man and the environment caused by pesticides' was broken up into manageable units. By following the 'Problem Tree' analysis, a highly controversial issue was translated into a series of technical problems to which there corresponded a set of 'adequate' solutions. First of all the damage to man and environment was seen as caused by the 'fact' that pesticides are not used 'judiciously' (Malaysian-German Pesticide Project 1993: 8). The assumption here, of course, is that for the problem to be solved one need not avoid the use of pesticides: that there exists a modality of pesticide use that will not damage man and the environment. By this technical operation all arguments for banning the use of pesticides were transcended.

Non-judicious use of pesticides was seen to have three causes: users' lack of knowledge regarding pesticides; farmers' neglect of consumer safety (despite knowledge); and the inadequate enforcement of pesticide legislation. Three broad solutions were proposed: education, monitoring of pesticide residues, and better enforcement respectively. The three general solutions suggested by the MGPP reflect the discussions and problematizations found in the Malaysian public sphere from the early 1980 s on how best to alleviate pesticide problems. 


\section{Education and Training}

Education of the farmers and plantation workers in relation to the use of pesticides came to be a pressing issue. Certain NGOs, such as the Environmental Protection Society of Malaysia, had urged the Ministry of Agriculture to start (a nation-wide campaign to educate farmers on the use of pesticides as early as the late 1970s (e.g. Sunday Mail, 18.11. 1979). However, it was not until the early 1980s, when the protests over pesticide poisoning proliferated, that the 'need' to educate the farmers became widely accepted. Thus, the leading national newspapers started to ask what had happened to the supposed commitment to educate the workers who handle the chemicals on the necessary safety measures (e.g. NST, 14.9.1983).

The need for education was supported by the Ministry of Agriculture. In August 1984 the Ministry promised to launch a major campaign to educate the public on the 'proper' handling and use of pesticides through talks, exhibitions and training sessions $(M M$, 17.6.1985), and the following year the Director General of the Ministry of Agriculture, Datuk Abu Bakar, argued that legislation alone would not prevent misuse of agricultural poisons, that what was more important was to educate its users on the 'proper' methods of usage (NST, 17.7.1985).

The following analysis of educational activities conducted by the Ministry of Agriculture deals only with the pesticide extension programme launched in 1988/89 under the MGPP. ${ }^{6}$ The ambitious goal of the programme was to train all Malaysian pesticide users (the number of which in the Report is estimated to be 500,000) in 'the proper handling of the products and train them in safety measures' (Malaysian-German Pesticide Project 1993: 102).

Participatory training was seen as the most promising technique for achieving the objective of the 'judicious' use of pesticides. Due to the changing objectives it was considered that the Training and Visit (T\&V) system, which had been applied successfully during the Green Revolution, would have to be replaced because:

The demands on agricultural extension in the future will be different. In many cases production levels will have reached a plateau where increases in input will no longer result in economical returns. Not increased production but increased efficiency and profitability will be the demands of the future. ... In such an agricultural system the 
extension services will no longer distribute technical packages, but they will have to assist the farmers on issues of farm management, quality, marketing and environmental conservation. These issues will have to be taught differently and the instrument of the T\&V system may no longer be adequate. Rather than teaching technology, the extension will have to raise awareness among its clients, affect their attitudes, broaden their understanding. For these tasks new tools will be required which will enable farmers to make qualified decisions rather than following instructions (Malaysian-German Pesticide Project 1993: 198).

Whereas the primary task of the $T \& V$ system had been to increase production via 'technology packages' taught to farmers through the extension system, the task was now to 'raise awareness among its clients, affect their attitudes', and 'broaden their understanding' so as to enable the farmers to make 'qualified decisions rather than following instructions'. Ultimately, participatory training techniques 'are more useful to motivate farmers than traditional teaching styles. Discussions and exchange of ideas with other farmers in a "field school" forum are more likely to change farmers' behaviour' (ibid.: 198). Whether the participatory techniques have been effective in changing the attitude and behaviour of the Malaysian farmers in relation to pest control remains to be evaluated (ibid.: 198-203). But as realized by the MGPP, the individual farmer's concern for production costs, short-term profit and the lack of 'viable' alternatives pose strong limitations to changes in his practices.

Perhaps the most interesting aspect of the participatory techniques is not their ability to generate the intended objectives, but the sophisticated manner in which an attempt is made to govern the farmer's thinking and behaviour. On the one hand, the participatory techniques may not differ much from the Training and Visit system, which has been utilized more or less unaltered since the introduction of modern pest control by the colonial administration at the beginning of the century (cf. Annual Reports of the Department of Agriculture). After all, both sets of techniques aim not only to change the behaviour and practices of the farmer, but also to instil in him a change in his 'attitude' and 'understanding'. In the first case this was supposed to impose on the 'indolent' and 'conservative' farmer a progressive, industrious and modern attitude; in the second case an attitude and understanding for safety, health and environmental concerns. 
On the other hand, the participatory training techniques aim to effect results in a much more sophisticated manner. Whereas the 'traditional' T\&V system in its most basic form aimed to increase production and productivity by unilateral lectures, introduction to preset solutions, and occasional visits by the Extension Officer, the participatory techniques aim to introduce new production standards of safety, health and the environment by discussions and exchange of ideas between farmers in field schools, games, brainstorming sessions and demonstrations (Malaysian-German Pesticide Project 1993: 216). Perhaps the MGPP's characterization of the participatory techniques as delineating a 'people-centred' approach is not quite misplaced. Under the motto that the judicious practices should be demonstrated not for, but by the farmers (ibid.: 215), the participatory techniques, by allowing the farmer to include knowledge and experience that he deems important, attempt to bring about the farmer's internalization of the desirable norms of safety, health and environment in a much more sophisticated manner than the T\&V system. Perhaps Deputy Agriculture Minister, Alex Lee, when commenting on the farmers' misuse of pesticides leading to Singapore's import ban, was being overly modest when he said that 'we can only give them guidance, advice and the benefit of our technical know-how' (cited in Sahabat Alam Malaysia 1987: 14). The participatory techniques introduced a few years later, whether successful or not, at least intended to instil in the farmers exactly what the Deputy Agriculture Minister had urged them to display, namely 'self-discipline' (ibid.: 14).

Governing the pesticide users was not a task for state agencies alone. With the pressure rising for a ban on its 'main revenue earner' (ICI Agrochemicals Public Affairs Adviser Encik Khalid, cited in NST, 6.7.1988), ICI Agrochemicals decided in 1986 to initiate its 'product stewardship programme' for the education of farmers and plantation workers handling pesticides. ICI Agrochemicals' definition of the programmes is: "The responsible and ethical management of a product during its progress from invention to ultimate use and beyond' (ICI Agrochemicals 1994). However, if 'carelessness', 'abuse' and 'misuse' of pesticides during its application were to be avoided, it was necessary to control not only the properties of the product, but also the behaviour of the individuals applying the product. What was to be managed, then, was not only 
the bio-chemical properties of the product, but also the 'knowledge', 'attitude' and physical practices of the farmers and plantation workers. Consequently, a series of educational techniques was deployed.

The first step taken by ICI Agrochemicals was to distribute 1,000 videotapes free of charge on the 'proper' handling of pesticides ( $M M$, 12.12.1986). A nation-wide programme to educate estate workers was launched in December 1986. Field personnel, including a doctor, were supposed to visit 600 plantations to give talks on the 'proper' way of handling pesticides ( $M M, 12.12 .1986)$. To what extent these plans were implemented remains uncertain, but by 1988 the efforts included competitions on how to store and use pesticides in the safest way, and visits by two doctors to about 200 estates annually (NST, 6.7.1988). A campaign was launched in 1989 to motivate the plantation workers on the 'habit' of reading product labels before purchase and use (BT, 23.5.1994). Three more elements were added to ICI's safety campaign in 1992. First, the preparation and distribution of 30,000 pictogram posters. By using small-scale pictures depicting real work situations, the posters aimed to make accessible to the often illiterate plantation worker the safe and proper use of pesticides. Second, a pesticide guidebook The Adventures of the Grow Safely Team aimed at schoolchildren, was to be distributed to at least 200 rural schools. Third, the Incentivized Learning Programme, targeted towards adult end-users of pesticides, consisted of various competitions and premiums related to the understanding of the pictogram posters (Star, 17.7.1992).

The educational programmes undertaken by ICI Agrochemicals, though no doubt the most comprehensive and enduring ones, were not the only programmes undertaken by the pesticides industry. The Malaysian Agricultural Chemicals Association (MACA) launched several initiatives from 1985, some independently and some in cooperation with ICI Agrochemicals. The four-day seminar 'Training of Trainers in Safe and Effective Agrochemicals Use' conducted in 1985 , was the first step taken by MACA, and aimed to 'create a pool of knowledgeable trainers who can educate Malaysians on the "proper" use of agrochemicals' (BT, 21.5.1991). MACA's efforts remained, however, on a rather limited scale until 1992, when a comprehensive programme was drawn up to educate more than 500,000 farmers on the correct use of chemicals (Star, 20.1.1992). Finally, it should be mentioned that Hoechst Malaysia's Agricultural 
Division by the early 1990s was organizing several hundred dialogue sessions with the farmers to educate end-users on the safe handling of pesticides (BT, 12.8.1994). In sum, educational techniques were a crucial modality to instil in the minds of the farmers and plantation workers an 'attitude' and 'understanding' of the necessity and desirability of applying pesticides in a 'judicious' and 'proper' manner. The effectiveness of the educational programmes in fulfilling their stated intentions remains unclear, and it has not been part of this article to try to evaluate this. What is clear though is that many NGOs claimed that the educational programmes were insufficient, in that they did not reach the majority of small farmers, and that many of those farmers who actually did participate in the programmes continued to utilize pesticides in an unsafe manner. More importantly, although education and training by many NGOs were seen as inadequate, and calls were made for more strict legislation and even the outright banning of pesticides, it seems that nobody ever contested the desirability and necessity of teaching the farmers and plantation workers how to apply pesticides in a 'safe' and 'efficient' manner. Education and training, in this way, had a strong legitimizing effect on the continued use of pesticides.

\section{Monitoring Pesticides in Food}

If education and training, as illustrated above, came to be seen as a necessary means to ensure the enhancement of 'knowledge' and 'understanding' of proper and safe use of pesticides, the doubt persisted whether that would suffice to bring about the desirable 'attitude', 'determination', or 'will' on behalf of the farmers and the plantation workers to ensure that the procedures prescribed were actually complied with. A Malaysian Agricultural Research and Development Institute researcher argued at the 'Seminar on Safe Handling and Efficient Utilization of Pesticides' that 'knowing and understanding alone does not guaranty [sic!] that pesticide application will be carried out in a safe and efficient manner. It demands will and determination on the farmer's or estate worker's part to do it right, which is something neither you nor I can be sure of' (Mamat 1989). In other words, the problem lay not so much with pesticides as a product as with the way that farmers and plantation workers were applying them. 
The MGPP likewise acknowledged that education was necessary but insufficient. Thus, it was realized that the farmers might neglect consumer safety 'despite knowledge'. But in contrast to the rather voluntaristic and disarming reason for this given by the researcher from the Malaysian Agricultural Research and Development Institute, the reasons suggested by MGPP were more susceptible to governmental intervention. Thus, the MGPP viewed the neglect of consumer safety despite knowledge to have two causes: offences are not detected, and profit is too strong an incentive. Although both these problems were acknowledged to be difficult to solve, they were none the less conceived to be susceptible to management. It was thus suggested that by building up technical capacity to facilitate the chemical analysis of pesticide residues in food samples, the monitoring and control of marketed food could be improved. Improved analytical capacity would at the same time target both the problem of detecting 'offences' of excessive levels of pesticide residues in food, and the problem of a 'too strong profit incentive', because:

If properly introduced and enforced, the new standards [of safety and quality] would then apply to all farmers equally and would not affect the individual's competitiveness. Only when the compliance of these safety and quality standards is left to the discretion of individual farmers will economic implications affect his decisions. The adoption of pesticide safety and quality recommendations is therefore more a measure of the prevailing enforcement climate than of their economic impact on the farm budget (MalaysianGerman Pesticide Project 1993: 193).

In other words, if the grid of control established through the monitoring of pesticide residues were made sufficiently impervious and uniform, the farmers would compete on equal terms at a higher level of safety. Consequently, the economic incentive for the individual farmer not to comply with the standards would be eliminated.

A fully equipped pesticide residue laboratory was established in Kuala Lumpur between 1984 and 1990 under the auspices of the Pesticide Section: after the setup of the Toxicology Unit in 1986, facilities to perform basic toxicological work were installed during 1987 (Malaysian-German Pesticide Project 1993: 88). By 1990 the laboratory had the capacity to analyse pesticide residues in food for about 70 active ingredients, including nearly all pesticides classified as 'extremely' or 'highly' hazardous by the WHO and registered for 
use in Malaysia (ibid.: 77). Two more laboratories were established in Sabah and Sarawak between 1990 and 1992, and by the end of 1993 the three laboratories had a combined instrumental capacity of approximately 20,000 analyses per year, though the number of analyses which were actually conducted was significantly lower (ibid:: 185-86). The skills of laboratory personnel, made up by several chemists and laboratory assistants, were upgraded through specific training in analytical methods both locally and overseas (ibid.: 77).

The Ministry of Agriculture was not the only government body involved in the monitoring of pesticide residues in food. When in late 1986 the formal responsibility for controlling pesticide residues in food was transferred from the Pesticides Board to the Food Quality Control Unit under the Ministry of Health, the latter Unit began to undertake the annual collection of several thousand food samples. These were submitted for testing to the Chemistry Department to see if the level of pesticide residues in the samples exceeded the Maximum Residue Levels, as defined in the Food Regulations 1985. On identification of any illegal residues in the samples, the Chemistry Department would issue analyst certificates to the Food Quality Control Unit for use in legal action (MACA Newsletter, 4 (3) 1991). However, legal prosecution and conviction seem to have been utilized in very few cases. While the political cost to the government was no doubt a major reason for the Ministry of Health's reluctance to prosecute farmers, the technical obstacles to trace the particular farmer 'abusing' pesticides came to be seen as a pressing issue.

\section{Enforcement: Tagging of Food}

If monitoring had contributed to the visibility of the problem of pesticide residues in food, the question remained of how to ensure that pesticides were applied in a 'judicious' manner to prevent infringements of the Maximum Residue Levels, as defined in the Food Regulations. In contrast to the plantation worker, who works under the supervision of an estate management and has little incentive to apply pesticides in a manner that would endanger either his own or others' health, the individual farmer whose agricultural practices are subject to infrequent checks by the Extension Officers, and whose 'motivation' is the quest for short-term profit, was seen as a far greater problem (cf. van Vreden and Ahmadzabidi 1986: 30; Malaysian-German Pesticide Project 1993). The many concerns voiced by the leading newspapers and the NGOs suggested that neither 
education nor occasional testing of the farmer's produce was seen as a sufficient guarantee for the avoidance of excessive residue levels. What was needed was a more effective system of deterrence: a system which would facilitate a speedy detection of pesticide 'misuse' by the farmer.

It remains obscure when the idea of tagging or labelling marketed food produce was first introduced, but when Singapore rejected Malaysian vegetables the suggestion was posed from several locations. For instance, a spokesman for the University Pertanian Malaysia's Centre for Agricultural Policy Studies suggested compulsory labelling of every container of vegetables as a first step towards grading Malaysia's vegetable exports. The labels should list the origin, producer's name, type and grade of vegetables, volume and date of packing. He argued that labelling would increase marketing efficiency and facilitate quality-control monitoring. The spokesman added that the 'sloppy' and 'loose' control of edible products was detrimental to the national image and, unless speedily and rigorously corrected, could adversely affect Malaysia's competitive edge (Star, 16.3.1987).

A tagging system was introduced in July 1987 for vegetables grown in the Cameron Highlands designated for export to Singapore. The initiative was supported by the leading newspapers. For instance, New Straits Times said that: 'One might go so far as to even advocate organic farming . . .', but that '[t]he goal for the moment should be to enforce these new rules and bring the errant farmers to book. This can only be done by constant spot checks' (NST, 16.7.1987). The fact that the tagging system applied only to produce exported to Singapore and not to produce designated for domestic consumption was criticized by a number of NGOs. Moreover, newspaper articles throughout the early 1990s regularly reported claims of the excessive levels of pesticide residues in vegetables and other foodstuffs due to the farmers' 'indiscriminate' use of pesticides, and argued for the 'need to monitor pesticides in food' (e.g. BT, 25.9.1991; Star, 30.3.1992; MM, 29.4.1992; NST, 16.2.1993; NST, 15.3.1994).

The first initiative to implement a tagging system for vegetables designated for domestic consumption was announced by the manager of Selayang wholesale market, the key distribution centre for vegetables marketed for Kuala Lumpur and Selangor. The 
manager announced that by September (1994) sellers would have to fill in new forms with details about chemical spraying, name and address of the farmer, date of harvest, etc.: 'With this information we shall be able to nail anybody selling vegetables contaminated with pesticides', because of a new laboratory that could supply the authorities with fast test results (NST, 4.4.1994). The following year saw the adoption of the Vegetable Marketing (Amendment) Regulations 1995. Director of Licensing of the Federal Agricultural Marketing Authority (FAMA), Ishak Abbas, said that once the Regulations came into force, officers from FAMA would conduct spot checks of vegetables at collection centres to ensure that they were tagged: 'Only genuine farmers who are registered with the department can buy them. Farmers will have to fill in their names, identity card number, address and name of the vegetable on the tag.' On the functioning of the system, Ishak Abbas said that purchasers would be fined if the vegetables they bought were not tagged. This form of 'indirect enforcement', argued Ishak, 'is a more effective method of enforcement as the purchasers will ensure that the vegetables are tagged by farmers so they (purchasers) will not get into trouble' (NST, 10.4.1995). ${ }^{7}$

It has not been possible to analyse the effects of the system as the Vegetable Marketing (Amendment) Regulations 1995 were still awaiting implementation at the end of 1995 . While it would be a rather futile attempt to speculate on the consequences that may be generated by this system, it seems appropriate to make a few remarks on the intended functioning of the system.

First of all the big advantage of the system, from the perspective of governing the farmers, is the huge potential for the centralization of control. Before 1987 the monitoring of the farmers' practices consisted in occasional visits by the agricultural Extension Officer. The introduction of more systematic collection of food samples for chemical analysis in 1987 did not change this mode of control significantly, because although the likelihood of detecting contaminated food increased, it was virtually impossible to trace the farmer who had delivered the contaminated produce. Ultimately, then, to ensure that the farmer in spite of unfavourable economic incentives applied pesticides 'judiciously', the control had to take place in the fields of each of the approximate 500,000 individual farmers at the exact moment when the pesticide was being applied; indeed, a hopeless task. In contrast, the tagging system allows 
control to be undertaken at a limited number of wholesale and retail markets. If enforced, the tag applied to each basket/container of food brought to the market by the farmer will allow for the unambiguous identification of the source of the produce. The combination of centralized control and unambiguous identification of the 'errant' farmer should make tagging both more efficient (in that the enforcement costs of the tagging system are far lower than for the extension system), and more effective (in that constant, uninterrupted and individualizing surveillance of the farmers' application of pesticides replaces the irregular visits by the Extension Officers and the collection of test samples, which only with great difficulty could be traced back to the individual farmer).

In short, substantial efforts were made during the 1980s to improve and expand the analysis and monitoring of pesticide residues in food, that is, to make visible the problem of pesticide residues in food. Chemical analysis and extensive monitoring would make it possible to enforce higher safety, health and environmental standards, that is, to sustain a desirable 'enforcement climate' that would enable the governing of the farmers' use of pesticides (Malaysian-German Pesticide Project 1993: 193). When monitoring turned out to be insufficient in controlling the problem of pesticide residues in food, a new technique, tagging, was developed to monitor the farmers' practices. From a historical perspective, it is hard to ignore the irony related to the changing 'need' to regulate the farmers' agricultural practices. Until two or three decades ago the farmer was conceived as indolent and conservative, and in need of a sense of productiveness and motivation regarding modern modalities of pest control; now the farmer, allegedly driven by 'too strong profit incentives' is seen to be in 'need' of re-education and subjection to what its proponents would like to be a panoptic apparatus, monitoring and controlling his conduct.

\section{Conclusion}

The transformation of bio-power in relation to the recasting of development discourses between 1945-55 made the issue of public health an object of knowledge and regulatory policy. This was a crucial precondition for the subsequent attempts to know, govern and contest the use of pesticides. In this process, scientific discourses came 
to play an important role in attempts to validate and invalidate arguments for and against the use of pesticides. The effect was to create a politics of expertise which, in effect, restricted the way that the use of pesticides could be contested. Moreover, the categories and assumptions in toxicological discourses pointed to the possibility of the continued use of pesticides in a controlled and safe manner. To avoid any misunderstanding: my argument is not that toxicological and medical discourses 'in themselves' determine whether or not pesticides are used and how this takes place. As illustrated above, these discourses have served both to legitimize claims for the continued use of pesticides, and to substantiate claims criticizing the use of pesticides. Rather the point is that these discourses - by producing certain techniques, such as controlled experiments and diagnostics, and certain notions such as hazard, Acceptable Daily Intake and Maximum Residue Levels - render possible certain modes of governing and managing the use of pesticides.

For the governmental rationalities displayed in relation to pest control, any obstacle to the achievement of a specified end had a technical solution. Should this solution have undesirable side-effects, such as the making of modern farmers driven by 'too strong profit incentives' and the poisoning of man and the environment by pesticides, new technical devices could be developed to deal with these issues as well. The curious thing, then, is not that plans, policies, laws and programmes, such as the Green Revolution, sometimes had quite horrifying unintended effects, but that in spite of this, governmentalities not only prevailed but became increasingly pervasive in relation to pests in agriculture. Thus, from the mid-1980s, the governing of men and pests in relation to each other was no longer a matter exclusively for the state: the NGOs pointed at the necessity of government to educate, monitor and control the use of pesticides so as to improve public health and safety, and the pesticide industry actually undertook the task of educating and training the farmers and the plantation workers in order to regulate their behaviour. An important effect of these initiatives was to justify the continued use of pesticides. More generally, the programmes and techniques deployed to protect public health from the adverse effects of the use of pesticides in Malaysian agriculture illustrate that modern governmentalities do not necessarily require a state apparatus to be translated into disciplinary practices. 
Peter Triantafillou, born 1964, M.Sc., Social Geography, University of Copenhagen, research fellow at the Centre for Development Research, Gl. Kongevej 5, DK-1610 Copenhagen V, Denmark. Fax: (45) 3325 8110, e-mail: ptr@cdr.dk, is currently working on a Ph.D. dissertation on the emergence and problematization of modern forms of pest control in Malaysia. He is also affiliated with International Development Studies at Roskilde University, Denmark.

\section{References}

Annual Reports of the Department of Agriculture, S.S. and F.M.S (19221938). Kuala Lumpur: Federated Malay States Government Press.

Annual Reports of the Federated Malay States (1895-1935). Kuala Lumpur: Federated Malay States Government Press.

Balasubramaniam, A. (1974) The Need for Pesticide Legislation in Malaysia. Kuala Lumpur: Ministry of Agriculture and Fisheries.

Balfour, Andrew and Henry Harold Scott (1924) Health Problems of the Empire. Past, Present and Future. New York: Henry Holt \& Company.

Boardman, Robert (1986) Pesticides in World Agriculture. The Politics of International Regulation. London: Macmillan.

Chan, K.W. and Cheong Izham, K.S. (1982) 'Paraquat Poisoning: a Clinical and Epidemiological Review of 30 Cases'. Medical Journal of Malaysia, 37 (3): 227-30.

Chester, G., and Woolen, B.H. (1981) 'Studies of the Occupational Exposure of Malaysian Plantation Workers to Paraquat'. British Journal of Industrial Medicine, 38: 23-33.

Colonial Development Act, 1929.

Colonial Development and Welfare Act, 1940.

Colonial Office (1944) The Planning of Social and Economic Development in the Colonial Empire. Papers on Colonial Affairs, C.M. no.3, April. London.

Conway, G.R. and Wood, B.J. (1964) 'Pesticide Chemicals - Help or
Hindrance in Malaysian Agriculture?'. Malayan Nature Journal, 18: 11-19.

Conway, Gordon R. (1991) Unzwelcome Harvest: Agriculture and Pollution. London: Earthscan Publications

Dean, Mitchell (1994) Critical and Effective Histories. Foucault's Methods and Historical Sociology. London: Routledge.

Department of Agriculture (1989) The AZ Guide to the Pesticides Act 1974. Kuala Lumpur: Dicetak oleh Utusan Printcorp.

Draft Development Plan of the Federation of Malaya (1950). Kuala Lumpur: Government Press.

First Malaysia Plan 1966-1970. Kuala Lumpur: Government Press.

Food Regulations 1985.

Foucault, Michel (1970) The Order of Things. An Archaeology of the Human Sciences. London: Routledge. (1979)

- Discipline and Punish. New York: Vintage Books.

- (1980) Truth and Power', in Power/Knowledge. Selected Interviews and Other Writings 1972-1977. New York: Harvester Wheatsheaf.

— (1990) The History of Sexuality. Volume 1: An Introduction. New York: Vintage Books.

- (1991a) 'Questions of Method', in G. Burchell, C. Gordon and P. Miller (eds.) The Foucault Effect. Studies in Governmentality. London: Harvester Wheatsheaf. 
- (1991b) 'Governmentality', in G. Burchell, C. Gordon and P. Miller (eds.) The Foucault Effect. Studies in Governmentality. London: Harvester Wheatsheaf.

Gill, Sarjeet Singh (1978) 'Pesticides and the Environment', in Development and the Environmental Crisis. Proceedings of the symposium 'The Malaysian Environment in Crisis' organized by The Consumers' Association Penang, The School of Biological Sciences, Universiti Sains Malaysia and Sahabat Alam Malaysia, held at Recsam Complex, Penang 16 Sept-20 Sept. 1978. Penang: Consumers' Association of Penang, 1982.

Gullick, J.M. (1969) Malaysia. New York: Praeger.

Hacking, Ian (1982) 'Biopower and the Avalanche of Printed Numbers'. Humanities in Society, 5 (384): 279-295.

Heidegger, Martin (1977) 'The Age of the World Picture', in The Question Concerning Technology and Other Essays. New York: Harper \& Row.

Howard, J.K., N.N. Sabathy and P.A. Whitehed (1981) 'A Study of the Health of Malaysian Plantation Workers Occupationally Exposed to Paraquatt'. British Journal of Industrial Medicine, 38: 110-116.

ICI Agrochemicals (1994) Unpublished overheads explaining ICI's product stewardship programme. 16.12.94.

Kennedy, J. (1962) A History of Malaya A.D. 1400-1959. New York: St Martin's Press.

MACA Newsletter, various issues.

Malaysian-German Pesticide Project Completion Report (1993) Unpublished report. Ministry of Agriculture Malaysia and Deutsche Gesellschaft für Technische Zusammenarbeit.

Mamat, Jusoh Mh (1989) Efficient and Safe Field Application of Pesticide. Paper presented at the seminar 'Safe Handling and Efficient Utilization of Pesticides', Kuala Lumpur, 15 September 1989.
Ministry of Health (1984) Annual Report 1983/84

Ng Tian Seng and Thong Kok Wai (1978) 'Paraquat Poisoning'. Medical Journal of Malaysia, 32 (4): 278-281.

Ong, S.H., Lim Guan Soon, U.B. Cheah and M.S. Sharom (1978) 'Trends and Problems Associated with Pesticide Usage in Malaysia', in Development and the Environmental Crisis'. Proceedings of the symposium 'The Malaysian Environment in Crisis' organized by The Consumers' Association Penang, The School of Biological Sciences, Universiti Sains Malaysia and Sahabat Alam Malaysia, held at Recsam Complex, Penang 16 Sept-20 Sept. 1978. Penang: Consumers' Association of Penang, 1982.

Pesticides Act 1974.

Pesticides (Registration) Rules 1976.

Sahabat Alam Malaysia (1981) Pesticide Problems in a Developing Country - A Case Study of Malaysia. Penang: SAM.

- (1987). A Commentary on Excessive Fungicide Levels Found in Different Types of Malaysian Vegetables. Unpublished paper. Penang.

Singh, Gurmit (1991) Where's the Greening? Kuala Lumpur: Amal Jaya Sdn. Bhd.

The Economic Development of Malaya (1955) Report of a mission organized by the International Bank for Reconstruction and Development. Baltimore: Johns Hopkins Press.

van Vreden, G. and Abdul Latif Ahmadzabidi (1986) Pests of Rice and Their Natural Enemies in Peninsular Malaysia. Wageningen: Pudoc.

Whitaker, M.J. (1989) 'The Handling and Use of Paraquat by Malaysian Rubber and Oil Palm Smallholders'. Joumal of Plant Protection in the Tropics, 6 (3): 23149.

Wood, B.J. (1968) Pests of Oil Palms in Malaysia and Their Control. Kuala Lumpur: Incorporated Society of Planters. 
- (1971). 'Development of Integrated Control Programmes for Pests of Tropical Perennial Crops in Malaysia' ,in C.B. Huffaker (ed.) Biological Control. New York: Plenum Press: 422-57.

\section{NOTES}

1 The notion of rationality is not utilized in the Weberian sense. Thus, there is no attempt here to uphold a typological division between formal and substantive rationality; nor does it refer to an abstract and inevitable process of formal rationalization of modern society (the 'iron cage'); and nor does it - and this is the most important difference - refer to the unitary and transcendental notion of Western rationalism. Rather, the term is utilized in a plural and instrumental sense. That is, rationalities are analysed as a multiplicity of means-end relations inscribed in and articulated through concrete practices (cf. Foucault 1991a: 79).

2 From 1985 to 1990 the enactment of a set of legally binding regulations, The Highly Toxic Pesticides Regulations, became an issue of major dispute. Under intense pressure from the NGOs and the media, the Pesticides Board under the Ministry of Agriculture drafted in 1985 the Highly Toxic Pesticides Regulations to force estate owners to provide better access to safety equipment and medical checkups for the plantation workers. Due to severe opposition from the pesticide industry and the estate associations, the Regulations were not implemented until 1996 and then only in a strongly modified version. Unfortunately this article leaves no place to analyse the struggle over these regulations.

\section{Malaysian Newspapers: \\ BT: Business Times \\ MM: Malay Mail \\ NST: New Straits Times \\ Star: The Star}

3 Guidelines on Toxicological Data Requirement for Pesticide Registration 1993: 1

4 Established in 1982 to 'end pesticide damage and support reliance on safe, sustainable pest management', PAN is an international network which by the early 1990s linked some 400 NGOs in 60 countries in both North and South. PAN coordinates campaigns on pesticides and their alternatives, and undertakes systematic documentation pertaining to scientific research on the effects of pesticides (and their alternatives) and the regulatory measures undertaken by national governments to control pesticides (PAN North America 1995).

5 This point is inspired by Martin Heidegger's reflections in The Age of the World Picture (1977).

6 Apparently the Ministry of Agriculture in 1984 launched a nation-wide campaign to educate farmers and plantation workers on the safe use of pesticides. However, material describing the campaign has not been published.

7 The article in the New Straits Times refers erroneously to the Vegetable Marketing (Amendment) Regulations 1995 as the 'Fruit and Vegetable (Packing, Labelling and Grading) Regulations 1995'. 